Int. J. Electrochem. Sci., 11 (2016) $7934-7946$

\title{
Electrochemically Activated Screen Printed Carbon Electrode Decorated with Nickel Nano Particles for the Detection of Glucose in Human Serum and Human Urine Sample
}

Subbiramaniyan Kubendhiran ${ }^{1}$, Subramanian Sakthinathan ${ }^{1}$, Shen-Ming Chen ${ }^{1, *}$, Chia Ming Lee ${ }^{1}$, BihShow Lou ${ }^{2,3 *}$, Pedaballi Sireesha, Chaochin Su,

${ }^{1}$ Electroanalysis and Bioelectrochemistry Lab, Department of Chemical Engineering and

Biotechnology, National Taipei University of Technology, No.1, Section 3, Chung-Hsiao East Road, Taipei 106, Taiwan (R.O.C).

${ }^{2}$ Chemistry Division, Center for General Education, Chang Gung University, Taoyuan, Taiwan (ROC)

${ }^{3}$ Department of Nuclear Medicine and Molecular Imaging Center, Chang Gung Memorial Hospital, Taoyuan, Taiwan (ROC)

${ }^{4}$ Institute of Organic and Polymeric Materials, National Taipei University of Technology, Taipei, 106, Taiwan.

Corresponding author

*E-mail: smchen78@ms15.hinet.net, blou@mail.cgu.edu.tw

doi: $10.20964 / 2016.09 .11$

Received: 27 May 2016/Accepted: 12 July 2016 / Published: 7 August 2016

A simple and sensitive amperometric enzyme-free glucose sensor was developed at the electrochemically activated screen printed carbon electrode (ASPCE) decorated with the nickel nanoparticles (NiNPs). We have applied simple electrochemical methods for the activation of SPCE, and the deposition of NiNPs on the ASPCE surface. The modified electrodes were characterized by the scanning electron microscope (SEM), energy dispersive X-ray spectroscopy (EDX) and electrochemical impedance spectroscopic methods (EIS). The electrocatalytic behavior of the modified electrode was studied by the cyclic voltammetry (CV), and amperometric method. The modified electrode exhibited good electrocatalytic behavior towards the oxidation of glucose with high oxidized peak current. In addition, the fabricated sensor exhibits the wide range of linearity between $5 \mu \mathrm{M}$ to $1.5 \mathrm{mM}$ with the high sensitivity of $1.9134 \mu \mathrm{A} \mu \mathrm{M} \mathrm{CM}^{-1}$ and the limit of detection (LOD) is $0.28 \mu \mathrm{M}$. The prepared ASPCE/NiNPs electrode shows the good selectivity in the presence of common interfering molecules. The practical feasibility of the sensor exhibited acceptable recoveries in determination of glucose in human blood serum and human urine. Moreover, the fabricated sensor shows good selectivity, reproducibility, and repeatability. 
Keywords: Activated screen printed carbon electrode, Nickel nanoparticle, Glucose, Electro catalysis, Electrochemical sensor, Human serum, Human urine.

\section{$\underline{\text { FULL TEXT }}$}

(C) 2016 The Authors. Published by ESG (www.electrochemsci.org). This article is an open access article distributed under the terms and conditions of the Creative Commons Attribution license (http://creativecommons.org/licenses/by/4.0/). 